\title{
Los aires, aguas y lugares en las Antigüedades de la Nueva España
}

\author{
Enrique Delgado López \\ Universidad Autónoma de San Luis Potosí, México \\ enrique.delgado@uaslp.mx
}

\begin{abstract}
Resumen
Francisco Hernández protagonizó, hacia 1570, una de las empresas científicas más importantes de la época moderna. Como parte de esta expedición recogió información sobre aspectos aparentemente ajenos a su formación científica; observó con peculiar maestría hechos que hoy reclamarían la historia o la antropología. En su observación a la cuenca de la Ciudad de México, plasmada en sus Antigüedades de la Nueva España, dejó un peculiar legado sobre los conceptos que la época le dictó, vigentes de alguna manera, acerca de la influencia del medio físico sobre el hombre.
\end{abstract}

Palabras clave: Francisco Hernández, México, historia de la ciencia, siglo XVI.

\section{Abstract}

Francisco Hernández was a protagonist, around 1570, of the most important scientific Enterprise of the modern epoch. During his expedition obtained information different to his scientific aim totality. Fact related to modern history and anthropology. His observation of México City basin was wrote in Antigüedades de la Nueva España are very interesting today, the ideas about the relationship between the physical environmental and society are current.

Key words: Francisco Hernández, Mexico, history of science, 16th century

\section{Introducción $^{1}$}

Las Antigüedades de la Nueva España es un texto que forma parte de la extensa y sólida obra escrita por Francisco Hernández, quien protagonizó una de las

El presente trabajo forma parte del proyecto Naturaleza y Cultura en la obra de Francisco Hernández, que fue posible gracias al apoyo que recibí de mi Universidad, por medio del programa del Fondo de Apoyo a la Investigación (FAI) 2006. 
empresas científicas más célebres y más fructíferas del periodo colonial, con resultados verdaderamente sorprendentes en el campo de la historia natural, pero que, como es evidente, no descuidó aspectos históricos o culturales, precisamente de las "antigüedades", del mundo que le tocó observar.

La aparición de un nuevo continente dejó de lado la concepción del mundo medieval, tripartita y cristiano, para concebir una cuarta parte, con enormes riquezas materiales y con otras formas de vida. El afán por conocerla guarda en sí mismo un tesoro de modernidad, expresado en el deseo por conocer los ricos y vastos lugares que ofrecieron a la Corona infinidad de recursos minerales, vegetales y animales, pero, sobre todo, humanos; además de innovar conceptos y métodos para estudiarla, los cuales se basaron, según All en G. Debus (18), en la observación directa.

Para ello, por una parte, el Estado moderno incentivó el conocimiento y las prácticas en torno a la naturaleza, de tal forma que comenzó a ser factor social y necesario en el afianzamiento y la consolidación del poder monárquico, principal articulador del control del territorio y de sus recursos naturales y demográficos. La idea era simple: para controlar un territorio es indispensable conocerlo, inventariar sus recursos naturales, experimentar nuevas técnicas para su aprovechamiento y aplicarse a la puesta en marcha de mecanismos de explotación que garanticen un rendimiento adecuado a los intereses del poder que quiere ejercer dicho control (Pardo Tomás 8 y ss.). Se abordó el mundo de la naturaleza viva mediante el cultivo de la entonces llamada historia natural. Se trataba principalmente de historiarla; es decir, de describir, catalogar y clasificar animales, plantas y piedras con un objetivo ambicioso y globalizador, preñado de interés por lo que el entorno inmediato ofrecía, pero también, de un modo inédito hasta entonces, por lo nuevo, lo raro, lo exótico (Pardo Tomás 8 y ss.).

Por otra parte, el humanismo europeo, en palabras de Ascención Hernández (8), trató de rescatar las ideas del mundo grecorromano buscando hacer de él el centro y medida universal, y valorar, a la vez, la perspectiva de cada ser humano. Es así como, habla la misma autora, en el encuentro de ambos mundos también coincidieron historias y culturas que se compartieron, como es propio del quehacer histórico. Culturas del Nuevo Mundo, en especial las de los Andes y de Mesoamérica, fueron estudiadas como realidades comparables, y en muchos casos comparadas, con las antiguallas de griegos y romanos. Al mismo tiempo que se llevaba un proceso de catequesis y cristianización de las naciones del Nuevo Mundo, se emprendía una singular tarea abierta a la comprensión integral de la naturaleza y el hombre de América (Hernández 8). José Pardo Tomás dice que "los europeos de finales del siglo XV y principios del XVI habían desarrollado una cultura científica basada esencialmente en los saberes filosófico-naturales 
procedentes de la Antigüedad clásica" (17), así como en la elaboración y transmisión del conocimiento acerca de la naturaleza, marcadas ambas por el escolaticismo universitario, ya que "la constante incorporación de los textos de los clásicos contribuyó a una profunda renovación, derivada esencialmente de la puesta en marcha - con apreciable y casi generalizado éxito - del programa humanista".

Los encuentros de nuevos mundos y culturas y la presencia de tendencias de pensamiento heredadas del mundo grecolatino y medieval forman el contexto en que está inmersa la figura de Francisco Hernández. Alumno de la Universidad de Alcalá de Henares, semillero de sólidas personalidades de la España del siglo XVI, tales como Bartolomé Carranza, Ignacio de Loyola, Tomás López Medel y Benito Arias Montano, se ha pensado que por su amistad, precisamente, con este último, su viaje a América no obedeció a razones estrictamente científicas, pues "bien pudo ser que, encubierto por las causas conocidas (deseo de exploración, curiosidad científica), exista una especie de exilio enmascarado provocado por su heterodoxia ideológica que lo hacía sospechoso (como a Sigüenza) a los ojos de la Inquisición; y si Sigüenza no pudo eludir el ser procesado, Hernández posiblemente soslayó con su viaje un destino similar" (Pardo Tomás 233) ${ }^{2}$.

Es sabido que la Complutense incorporó el pensamiento renacentista a la vida intelectual de la península. Hernández perteneció a esas primeras generaciones de jóvenes médicos españoles que conocieron, traducidos al latín, las obras de Hipócrates, Galeno y Avicena (tres hombres, tres épocas, tres culturas), cuyas ideas sobre la salud y la enfermedad estaban vigentes en la medicina renacentista.

Su estancia en la Nueva España abarca desde 1570 hasta 1576, años en los que se abrió camino para generar más de 15 volúmenes con diversos temas; particularmente, de historia natural, donde incluye pinturas de la herbolaria mexicana. A ello suma, además de las Antigüedades, la traducción de la Historia natural de

Trabulse habla de las simpatías de Hernández por el grupo de la familia del amor o familia charitatis, que "oficialmente pertenecía a la iglesia que imperaba en la región donde vivieran sus miembros", aunque "indiferentes a toda clase de dogma eclesiástico". Este grupo no era partidario de "los extremismos fanáticos de católicos, protestantes o calvinistas", y se dedicaba al "estudio y eran dados a experiencias devotas profundas. No buscaban prosélitos y se alejaban de las mayorías. Era un grupo selecto, neo-estoico y de proclividades quietistas" (231-232). El tema también es tratado por Germán Somolinos, su principal biógrafo, al decir que "de ser cierta la hipótesis anterior, de la que como decimos no podemos hacernos solidarios por no poseer un solo dato concreto que haga pensar así, tendríamos entonces que admitir que el viaje de Hernández a México y su fructífera expedición enmascaraban la realidad de uno de tantos exilios de españoles como ha tenido que acoger la generosa tierra de América y que, desde entonces hasta hoy, se han venido repitiendo entre los naturalistas y científicos españoles con dolorosa periodicidad" (147-148). 
Plinio, unos Trabajos filosóficos y un Método cristiano, así como un estudio Del Cocoliztli y otro De Peces, más una descripción de Asia ${ }^{3}$.

El libro de las Antigüedades de la Nueva España, según Ascensión Hernández, "constituye tema principal de descripción y análisis" en el que el médico plasma sus "recuerdos de experiencias personales, aquello que contempló o supo de primera mano"; y en él deja testimonio de su aprendizaje "sobre la historia y la cultura de los aztecas o mexicas y de sus vecinos". Expresa también sus reflexiones de corte histórico, hasta hoy relativamente poco tomado en cuenta a la par con otras crónicas de América y, en particular, de México; acentúa su misión como científico en el deseo por conocer "lo más detalladamente posible la realidad geográfica, histórica, social y económica" de los enormes territorios españoles (16).

Por su parte, Miguel León Portilla, en otro estudio introductorio, este en el marco de la edición de las Obras completas ${ }^{4}$, respecto al texto que nos ocupa, dice que, en conjunto, la obra del protomédico del rey Felipe II "fue concebida con hondo sentido a la vez cultural e histórico" (39), visto por el aprecio de Hernández a la obra del fraile Bernardino de Sahagún, sirviéndose de ella a tal grado que incluso "llegó a copiar y traducir al latín algunas secciones completas de lo elaborado" por el franciscano. Pero si bien es cierto que en algunos casos transcribió párrafos, como era frecuente en la época, también hay dignos aportes que deben valorarse (León Portilla 40).

Los escritos "sobre antigüedades indígenas y acerca de la Conquista constituyen aportaciones hasta hoy poco tomadas en cuenta", aunque es necesario aceptar

3 A pesar de su variada obra, los escritos sobre ella son más bien escasos. Desde luego que esto no se aplica a su historia natural, que desde su concepción ha sido tratada por diversos autores a lo largo del tiempo, sin dejar de recordar que su obra, en ocasiones mutilada, pero siempre valorada por su erudición, peregrinó durante siglos, penuria que finalizó con el proyecto de las Obras completas de Francisco Hernández, protomédico e historiador del rey de España, don Felipe II, en las Indias Occidentales, Yslas y Tierra Firme del mar Océano, encabezado por Germán Somolinos y Efrén C. del Pozo. En la actualidad, José María López Piñero y José Pardo Tomás han contribuido al estudio de la obra de Hernández con varios textos; destaco sólo los siguientes: Nuevos materiales y noticias sobre la historia de las plantas de Nueva España, de Francisco Hernández y La influencia de Francisco Hernández (1515-1587) en la constitución de la botánica y la materia médica modernas. Por su parte, Raquel Álvarez Peláez hace una importante contribución al estudio del proyecto encabezado por Hernández en el ámbito de la ciencia española, particularmente enfocada al conocimiento de la naturaleza Americana. El nombre de su texto es más que elocuente.

$4 \quad$ Miguel León Portilla. "Introducción a las Antigüedades de la Nueva España y Libro de la conquista de la Nueva España". En Obras completas. Op. cit., t. VI, Escritos Varios, 1984, p. 39. En esta Introducción, León Portilla hace un valioso recuento de la publicación y ediciones del texto desde el siglo XIX hasta el proyecto que llevó a cabo la UNAM de la edición de las Obras completas, de Francisco Hernández. 
"que ni las Antigüedades ni el libro de la Conquista pudieron ser fruto de investigaciones, detenidas y directas, como las que habían emprendido ya algunos frailes y otros cronistas", como el propio Sahagún, Motolinía, Pomar y López de Gómara (León Portilla 40).

Según León Portilla, las contribuciones originales plasmadas en las Antigüedades se encuentran en los capítulos XXI, "Cómo era la ciudad de México cuando al principio la ganaron los españoles"; XXII, "Cómo era la ciudad de México en el año de quincuagésimo más o menos de que fue ganada"; XXIII, "Del clima de la ciudad de México"; XXIV, "De las cosas admirables de la Nueva España"; XXVII, "De los mercados" y el XXVIII, "Del uso de qué cosas conocidas en el antiguo continente carecían los mexicanos en el tiempo que se rindieron a nuestras armas". En el libro segundo destacan, por su originalidad, los capítulos II, "De los médicos que llaman Titici"; VI, "Del Nitoteliztli"; XI "Del origen de la gente de la Nueva España"; XII, "De la ciudad y de los reyes de Tetzcoco" y XIV, "De otras cosas que realzan el ornamento de la ciudad tetzcocana".

Valga este momento para manifestar que el presente trabajo es un acercamiento al estudio de esos títulos, donde, a propio parecer, confluye el científico con el humanista, al dejar constancia de su observación de la relación entre la naturaleza y la sociedad que en el tiempo y en el espacio le tocó observar, con claras herencias hipocráticas. En estos capítulos cobran relevancia sus observaciones sobre diversos aspectos de la ciudad de México, así como la influencia del aire en el comportamiento de los hombres, como parte de ese espíritu vital, ideas que se han extendido aún a los tiempos recientes, sin dejar de lado la diversidad del paisaje, la descripción que hace de los indios vivos y de su comida y costumbres.

\section{El problema de escribir sobre las Antigüedades}

En el proemio a las Antigüedades de la Nueva España, Francisco Hernández se dirige a su monarca para indicarle que

Aún cuando me hayas comisionado tan sólo para la historia de las cosas naturales de este orbe, Sacratísimo Rey, y aunque el cargo de escribir sobre antigüedades, pueda considerarse como que no me pertenece, sin embargo, juzgo que no distan tanto de ella las costumbres y ritos de las gentes porque aún cuando en gran parte no deban atribuirse al cielo y a los astros, puesto que la voluntad humana es libre y no está obligada por nadie sino que espontáneamente ejecuta cualesquiera acciones. (57)

Con la carencia de los elementos para escribir sobre el tema, no deja de lado confesar que le es "difícil" escribir: 
Los ritos de estas gentes [son] tan varios e inconstantes, que apenas algo firme y continuo pueda transmitirse y que esto mismo apenas pueda arrancarse a estos hombres, porque o cuidándose ellos mismos u odiándonos a nosotros, esconden en arcanos lo que tienen conocido e investigado, o porque olvidados de las cosas de sus mayores (tanta es su rudeza y desidia) nada pueden contar de notable. (57)

El afán y el deseo por encontrar esos secretos lo llevaron a trabajar con empeño, a reconocer que su obra "sin esta parte no puede quedar concluida en todos sus números", por lo que buscó "la claridad y recreo para los nuestros que viven en este mundo". Debido a ello, para no faltar "completamente a esta parte y que no había echado algunos fundamentos a una fábrica que tal vez dilataré y aumentaré en los días futuros", le dice a su Monarca, que el texto de las Antigüedades es una "semilla de historia, cualquiera que sea transmitida, sí no con la facundia que conviniera al menos con la que fue dada por mi fe y afecto no común hacia tu Majestad" (Hernández 57).

Es necesario entender que al no escribir sobre las Antigüedades, hacer a un lado la parte humana o moral en su obra era faltar al entendimiento del cosmos cristiano del siglo XVI. La historiografía brinda herramientas para ahondar en esta línea. Edmundo O'Gorman, en su estudio introductorio a la Historia Natural y Moral de las Indias, de José de Acosta, clarifica el tema de la conexión de ambos mundos, el natural y el moral. Revela, para el caso de Acosta, que no explicitó la razón de los vínculos por parecerle obvia, pues el jesuita daba por supuesto el fundamento de aquella relación entre ellos, ya que su estudio guarda en sí mismo una unidad. La estructura del libro "consiste en una peculiar manera de concebir la realidad universal como dotada de una organización interna que permite reducir a unidad todas sus partes o, lo que es lo mismo, a la infinita variedad de los fenómenos, cualquiera que sea su diversidad o novedad" (xxxvi).

De esta manera, el cosmos se organizaba a base de un mundo mineral, vegetal y animal, además del humano, por lo que hacer un tratado del nuevo mundo era enfrentar este esquema. Hernández, en el libro de las Antigüedades, supo dar razón al enlace entre la naturaleza y el mundo moral de acuerdo con lo escrito por O'Gorman'.

En el campo de la medicina se encuentra esta relación, se plantea en términos de herencia hipocrática, "por la cual se elaboraron arquetipos geográficos a partir

La misma relación se encuentra, por ejemplo, en el Reportorio de los tiempos, de Enrico Martínez, de 1606. En el índice de este texto se aprecia el desarrollo de ese enlace del mundo natural con el mundo moral. 
de los que se derivaba una condición física, una condición moral y un destino para los individuos y los pueblos" (Arismendi).

Germán Viveros (19) escribe que los hipocráticos consideraron a la naturaleza "bajo dos facetas: una de carácter universal o macrocósmico, y la otra de índole individual o microcósmica". La primera, aquella que se ocupaba de su conocimiento, la entendieron como un conjunto de cosas, fenómenos y fuerzas que componen el universo; la segunda, la ocupada precisamente por la naturaleza humana, la de cada individuo, la correspondiente al microcosmos, equivale a su fisiología. Así, esta podía considerar la naturaleza de cada ser en particular, como también la del varón y la de la mujer, en general, igual que la de los jóvenes o viejos, o la de los miembros de razas distintas.

El mismo Viveros explica que "una y otra naturaleza eran principios actuantes en ámbitos diferenciados y delimitados, que se hallaban en permanente relación, sobre todo el primero respecto al segundo, al punto de que aquel determinaba, no sólo la naturaleza correspondiente a cada ser o cosa, sino también su peculiar índole" (19). Arismendi menciona que ambos cosmos, el micro y el macro, expresaron "la influencia del medio y sus agentes, aire, vientos, clima en el temperamento y la sanidad".

Resulta, entonces, que la unidad cósmica es indisoluble, y un adecuado equilibrio entre las partes es una mejor relación entre el mundo natural y el individuo, esencia del pensamiento hipocrático. El problema aquí es cómo observó Francisco Hernández la naturaleza de la ciudad de México. Lo hizo como lo aconsejan los tratados hipocráticos, y agudizó sus sentidos en los aires, los suelos, la forma de las casas y la orientación de los lugares. Acorde con los consejos que Hipócrates dio a sus aprendices, pues ellos han de

...conocer los vientos, calientes y fríos, especialmente los que son comunes a todos los hombres y, además, los típicos de cada país [...] así cuando se llega a una ciudad desconocida es preciso preocuparse por su posición: cómo está situada con respecto a los vientos y a la salida del sol [...]. Partiendo de todos esos puntos hay que ocuparse de cada dato por separado, pues si uno los conociera perfectamente - mejor todos, pero, si no, los más posibles-, no ignoraría al llegar a una ciudad que desconoce, ni las enfermedades locales, ni cuál es la naturaleza de las afecciones comunes. (105-107)

Francisco Hernández no ignoró esas variables de la tradición hipocrática, y las puso en práctica durante su visita a México; reconoció, como se verá adelante, las aguas y los vientos de la ciudad de México y Texcoco, y advirtió que la 
"Nueva España tenía una naturaleza que predispone a la degeneración del cuerpo y del alma" (Ramírez). Esta idea estará vigente a lo largo del virreinato y de la historia decimonónica mexicana. Esta degeneración será, como es bien conocido, uno de los temas del debate del siglo XVIII entre los naturalistas europeos de escritorio, como Cornelio de Paw y el Conde de Buffon, y los estudiosos americanos, como, en el caso de México, el jesuita Francisco Javier Clavijero ${ }^{6}$.

\section{La "posición" de la ciudad de México en las Antigüedades de la Nueva España}

Francisco Hernández llegó a la Nueva España en 1571 como principal protagonista de una de las empresas más importantes, con "una misión que no era diplomática, ni secreta, ni de estado, ni religiosa [...] la misión de Hernández era científica" (Somolinos, 159). Por primera vez, en sentido estricto, el paisaje natural americano habrá de ser leído, y — parafraseando a Juan Pimentel— Hernández, como científico, desplaza no solo su cuerpo a través de mar y tierra, sino también sus instrumentos y su conocimiento, para luego redactar su obra, "momento decisivo de poner por escrito sus relaciones, descripciones o teorías frutos de sus viajes".

Después de una brevísima estancia en Veracruz, el día primero de marzo de ese año presenta a la Audiencia su título de protomédico, para, de inmediato, iniciar sus trabajos. La capital del virreinato llama su atención, y los diversos elogios no se hacen esperar. Somolinos, contrariado, reflexiona al respecto y destaca los pocos edificios terminados, la discontinuidad en las calles, los modestos y pocos conventos; en fin, una ciudad lejana de la denominada "de los palacios", apelativo ligado a siglos posteriores de la historia de la capital virreinal ${ }^{7}$. Pero aun así, Hernández admira la ciudad, y las razones para ello, según el propio Somolinos, son el "clima apacible, siempre en primavera, la abundancia de vegetación, la belleza de las plantas, florecidas durante todo el año"( t. I 64).

La ciudad de México, a los ojos de Hernández, está en razón a la laguna, la que "parece hervir con chalupas volando de aquí para allá [...] llevando lo necesario para la vida de las poblaciones vecinas y limítrofes"; la ubica "en longitud

Para este tema véase Antonello Gerbi. La disputa del Nuevo Mundo. Historia de una polémica 1750-1900. 2 $2^{\mathrm{a}}$. edición, FCE, México, 1993.

7 Una descripción de la ciudad de México, contemporánea a la que visitó Francisco Hernández, se encuentra en Francisco Cervantes de Salazar. México en 1554 y Túmulo imperial [edición, prólogo y notas de Edmundo O'Gorman], Buenos Aires: Porrúa, 1963. Otra edición es: Francisco Cervantes de Salazar. México en 1554: tres diálogos latinos [Introducción Miguel LeónPortilla, versión castellana de los diálogos de Joaquín García Icazbalceta], México: UNAM, 2001. 
noventa y siete grados y cuarenta y cinco minutos" del meridiano de Toledo. Cuenta con "moradas fuertes, amplias y dignas de ser vistas"; además, destaca con desdén las "mediocres habitadas por los indios", que se cuentan en número de 20.000. En esta ciudad de lagos y chalupas descansa todo lo egregio que pueda ser encontrado en las ciudades florecientes de la Península.

Distingue una urbe indígena y otra española. Como unidad, la observa de acuerdo con los edificios, los caminos, la calidad del agua y el clima. Comienza por cuantificar y destacar la calidad de sus construcciones, que al extender el argumento diferencia estratos sociales; dice que la ciudad, cuando fue ganada por Cortés, tenía "sesenta mil casas o más [...] fabricadas muy diestramente con piedras y vigas, templos, palacios reales y casas de próceres, las demás eran bajas, estrechas y carecían todas de puertas y ventanas".

La ciudad funcionaba con caminos mixtos, hechos de tierra y agua, que conectaban las casas con el lago, en un ejemplo de convivencia entre el medio natural y la cultura humana, que le daba fluidez al intercambio de mercancías, sin dejar de lado las tareas cotidianas de la población. Por ello, la casa, como tal, contaba con dos puertas: "la una que daba a la vía pública por tierra y la otra a la que bañaban las aguas"; parecidas circunstancias, según Hernández, las tenían Venecia y Amberes.

La ciudad no solo se dividía entre el agua y la tierra, sino que, al estar en razón con la laguna, también se rompía en cuanto a lo salobre del líquido, así como a su nominación. Es decir, al descansar en un gran valle, asiento del cuerpo lacustre, la ciudad se alimentaba de agua salada "completamente inútil para beber, aun cuando afluyan a ella manantiales y ríos de agua dulcísima y gratísima; ya sea por las crecientes que de los montes que rodean la ciudad se precipitan copiosas y estancadas se pudren". No olvida que se surte de agua dulce del manantial de Chapultepec. Como buen científico dedicado a la historia natural, observa que el agua salada abunda en nitro y en sal por la naturaleza de su álveo, y no por otras causas inanes que algunos soñaron.

Ante la posibilidad de no contar todo cabalmente, prefiere la prudencia, para no describir muchas cosas que "debían ser pasadas en silencio, tanto porque callarlas es más seguro que decir poco de una ciudad famosísima; cuanto para que no se considere que hablo de ella como amigo, más que describirla como equitativo censor o juez con sus propios y merecidos colores".

Sobre el clima de la cuenca, de acuerdo con su punto de vista, es intermedio "entre frío y caliente, pero un poco húmedo debido a la laguna", que por ello se manifiestan condiciones de podredumbre, tanto que "los llamados "puntos o 
exantemas', que suelen acompañar a las fiebres, son peculiares", además de que "el dolor de costado, grave en verdad en esta región, las infecciones de los riñones y de la vejiga, la disentería y la diarrea son allí generalmente mortales". Los alimentos, dice, son más húmedos y copiosos que agradables al gusto, aun cuando gustan a los que se han acostumbrado, probablemente en relación con los españoles que les encuentran sabor.

Pero a pesar de ese clima húmedo que provoca enfermedades y produce abundantes, pero sugestivos, alimentos, reconoce que "apenas hay en el orbe una ciudad que por la copia de los alimentos (para no hablar del oro, de las piedras preciosas y de la plata), y por la abundancia de los mercados y del suelo pueda ser comparada con México. ¿Qué más? Dirías estar en un suelo ubérrimo y fertilísimo de tal manera brillan y abundan todas las cosas, con penuria de nada y con fertilidad y abundancia de todo".

Después de este reconocimiento acerca de una ciudad que lo tiene todo, manifiesta una clara contradicción en relación con sus habitantes. Resalta las distinciones en razón a "las inteligencias superiores de los españoles" que se contraponen a la naturaleza del indio, individuos en su mayoría "débiles, tímidos, mendaces, viven día a día, son perezosos, dados al vino y a la ebriedad, y sólo en parte piadosos [...] de naturaleza flemática y de paciencia insigne", aunque reconoce que son hábiles en el aprendizaje de las artes "aún sumamente difíciles y no intentadas por los nuestros", imitan cualquier cosa sin ninguna ayuda. Se lamenta de los que nacen "en estos días" y que a su vez empiezan a ocupar estas regiones, pues, ya sea que deriven su nacimiento únicamente de españoles o que "nazcan de progenitores de diversas naciones, ojalá que obedientes al cielo, no degeneren, hasta adoptar las costumbres de los indios".

Pero si bien desprecia la naturaleza mexicana, sucumbe inconscientemente a la variedad y la experiencia de vivirla; particularmente, por lo diverso. En primera instancia repudia el cielo, clima y hombres, pero pronto olvida el repudio, o lo desconoce, y llama su atención que "en un intervalo de tres millas se encuentren tantas temperaturas diferentes; aquí te hielas y allá te quemas; no por razón del cielo, sino de la situación y de los valles, a los cuales toca en suerte un cielo muy adecuado, casi templado", condiciones que repercuten en la agricultura, ya que "estas regiones producen dos cosechas anuales y hasta tres, porque en el mismo tiempo que aquí domina el frío, allá el calor está en vigor y en otra parte una temperatura primaveral acaricia a los hombres y a los otros seres vivientes". Finalmente se pregunta:

¿Qué diré de las admirables naturalezas de tantas plantas, animales y minerales; de tantas diferencias de idiomas, mexicano, tezcoquense, otomite, 
tlaxcalteco, quexteco, michoacano, chichimeca y otros muchos que apenas pueden ser enumerados y que varían con brevísimos intervalos de terreno; de tantas costumbres y ritos de los hombres, de tantos vestidos con los que se cubren y modos y maneras de otros ornamentos que apenas pudiera seguirlos la inteligencia humana [...] cuando la verdadera imagen sólo puede ser comprendida por los presentes por la experiencia misma y como lo mismo son ofrecer y representar?

Describe a los indígenas mexicanos con "mediana estatura, de color rojizo, ojos grandes, ancha frente, narices muy abiertas, nuca plana, pero ésta se debe a la industria de los padres; cabellos negros, grasosos, flexibles y largos y aquellas partes que suelen ser cubiertas con pelo, en gran parte vellosas o completamente lampiñas". Los chichimecas no "admiten mercaderes extranjeros"; no soportan el hambre y el trabajo, y, al igual que los mexicanos, son "dóciles y de tolerancia insigne $[\ldots]$ son dulces aduladores, y obedientes cuando se les obliga por la fuerza y por el miedo". Destaca su religiosidad, pero pronto la contrapone por ser "matadores y devoradores de hombres" y "se dan a la lujuria aun cuando sea masculina, y ni se avergüenzan de tan portentosa libídine ni castigan un crimen tan grande".

Las mujeres emulan con gusto el color y el gesto de sus maridos. Se dejan crecer el cabello, que "acostumbran ennegrecer con cierto género de lodo en gracia de la pulcritud y para extinguir unos feos animales que nacen en la cabeza", con los cuales "a veces suciamente se alimentan y los engordan en la cabeza". Tienen la costumbre de contraer matrimonio "cuando sólo tienen diez años y son propensísimas a la lujuria"; procrean a muy temprana edad y tratan "de tener los pechos muy grandes y colgantes", para que "los hijos puestos sobre los hombros puedan mamar con facilidad la mayor parte del tiempo". No tienen afición al vino y, como acontece en otras naciones, son más temperantes que los hombres.

En todos los barrios de la ciudad, dice Hernández, "hay una plaza anexa en la cual cada quinto día, o con más frecuencia, se celebran mercados", hecho que se repite "también en las otras ciudades y poblados de la Nueva España". No hay duda de que el más grande era el de Tlatelolco "de casi sesenta mil hombres", y le sigue el de Tenochtitlán, en el que "ningún día dejaba de congregarse numerosa turba de varones y mujeres para la compra y venta de varias cosas." Además, "también las vías públicas cercanas hierven con mercancías", donde se encuentran "muchísimas cosas sumamente variadas y a veces también muy insignificantes y de poca importancia, según lo quiere la moda, porque en verdad así es el ingenio de los hombres y de tal manera dispuesto por la naturaleza que lo que unos estiman de gran valor para otros es cosa de risa y desprecio". 
En cuanto a la comida, vale la pena reflexionar sobre lo que pensaron quienes leyeron el siguiente pasaje: si acaso los reales ojos del rey o los nobles de su corte, o bien los curiosos hombres interesados por conocer más de la naturaleza del Nuevo Mundo. Habla Hernández:

¿Y de qué cosas no extraen comida para exponerla a la venta? Son raros los animales que perdona su paladar, puesto que se alimentan aun de serpientes venenosísimas, después de que les han cortado y desechado las cabezas y las colas; de perros, de topos, lirones, lombrices, piojos, ratones, musgo lacustre, sin que quiera yo recordar el lodo lacustre y otras cosas de la clase de los animales y plantas, hórridas y nefandas [...] hay tantas tabernas que es de admirarse que tanta mole de carne pueda ser consumida y devorada por los ciudadanos, cuando además abunda el pescado crudo y cocido y en tortas de maíz y tortillitas de maíz y de huevos de varias clases de aves; maíz cocido, crudo y en mazorca en gran cantidad, así como de raíces, habas, frijoles y legumbres. No pueden ser enumerados los géneros de frutas indígenas o de nuestro país, secas y frescas que allí se venden, y la que es tenida en mayor aprecio que las demás es el cacaotal, del que se habla más por extenso entre las plantas.

Según Hernández, los indígenas no conocieron "pesas ni medidas y carecían de moneda metálica, usando el trueque o la semilla del cacaotal". Lo mismo sucedió con el hierro; usaban solo la madera, piedras y "a veces el bronce". Los navíos de gran calado estaban ausentes, exceptuando "las llamadas canoas, es decir, troncos excavados a manera de esquifes largos". No conocieron el vino a la manera de los europeos, pero sí degustaron "otros muchos diversos, muy sabrosos al gusto y que se suben a la cabeza con vehemencia". Carecieron del caballo y su escritura era a base de "las diversas cosas que los griegos llaman jeroglíficos".

Para él, los indígenas no usan vestidos cómodos, zapatos, calzoncillos, cáligas, gorros, túnicas ni cualquier otra materia con que se pudiera cubrir el cuerpo, excepto mantos, de los cuales no les estaba permitido usar todos. La lista de carencias se extiende también a las armas arrojadizas de acero, a las que llama defensivas: espadas, cuchillos, máquinas bélicas; y con elementos arquitectónicos como puertas y ventanas. Si bien admiró la variedad de la comida, reconoce que no tuvieron "carne de buey, de carnero y cabras de las nuestras, de jabalí y de puerco y de casi todos nuestros frutos y legumbres".

Juzga que no cultivaron leyes justas y estatutos útiles "para gobernar bien y regir la república y de gran parte de las artes necesarias, y lo que era más miserable, del conocimiento y del culto del verdadero Dios y de la doctrina y observancia de la verdadera religión, y de otras no pocas cosas de este mismo orden, que a 
nadie puedan parecer innecesarias para pasar feliz y sin culpa la vida del alma y del cuerpo". Estas cosas, tan importantes en la vida europea, no estaban en la vida indígena, por la "desidia de ellos, que después de tantos siglos de la creación del mundo, han permanecido en tanta rusticidad".

Hernández refiere el conocimiento de los cielos, y dice que "del sol, de la luna, de la estrella de Orión, de Venus, de las Osas, y de los otros astros en los que creían que habitaba un numen, no sabían casi nada"; lo reduce todo a un conocimiento vulgar, solo reverencia "los eclipses y meteoros y cualquiera otra cosa semejante". Entre sus presagios estaban los meteoros y fenómenos generados en lo más alto del aire, pues creía "que las nubes blancas en las cumbres de los cerros presagiaban el granizo y las nubes densas la lluvia". La escarcha, según el pensamiento indígena, cayendo como rocío, anunciaba la fecundidad de tal año, y el arco iris, un "tiempo tranquilo sereno y el término y fin de las lluvias"; en cambio, las estrellas fugaces anunciaban "las vicisitudes de los reyes y de los reinos".

No evita hablar sobre el origen de la gente de esta Nueva España, en aras de encontrar un argumento para unirla al mundo europeo y, como parte de toda una ideología, justificar la presencia española en estas partes del mundo. Hernández enuncia que la nación más antigua es la de los chichimecas, pero su nombre cambió "por sus matrimonios con otras razas". Relata sus formas de vida y se sorprende de que "hasta el día de hoy gran número que vive así y no ha movido lo ancho de un dedo el ánimo para entrar a una vida más civilizada", adorando al sol "como primer numen". No desconoce que eran fieros y excelentes en "valor guerrero, por lo que dominaron toda esa región".

Después de ellos, bajó a esos lugares una gente fuerte y mucho más civilizada, con el nombre de los de Aculhuacán, que "se establecieron en un lugar campestre y llano, donde permanecieron en tiendas de campaña muchos años, aun cuando divididos en batallones y falanges", para luego emigrar, "por mandato de los dioses", hacia el Oriente y el Septentrión. Pasado el tiempo, "poco más o menos ochocientos años, llegaron a estos lugares, no todos a un tiempo, sino unos después de los otros con espacios de centenares de años", los texcocanos, los de atzcapotzalco y luego los mexicanos, que "se establecieron entre los de Atzcapotzalco y los de Tezcoco en unas islas muy pequeñas de la laguna mexicana"; Hernández dice:

Hay quienes aseguran que todos éstos vinieron de Palestina, atravesando un angosto mar, de las diez tribus que Salmanasar, rey de los asirios, condujo cautivos a Asiria, reinando en Israel Oseas y en Jerusalem Ezequías, como se lee en el libro cuarto de los Reyes, Cap. Décimo Séptimo, hace más de dos 
mil doscientos años, lo cual aunque sea incierto, no me parecen conjeturas que deben despreciarse del todo.

No duda de lo anterior, y, como en muchos otros textos, busca las explicaciones de sus conjeturas cayendo, en un primer caso, en la lingüística, pues para él hay palabras en los idiomas indígenas "que o son hebreas o muy semejantes a las hebreas como si procedieran de ellas". En segundo lugar, con base en la misma Sagrada Escritura, llegaron al lugar adonde se dirigieron, después de caminar a pie durante seis meses. En tercero, los nombres, no de otra manera que entre los hebreos, se imponían por deliberación del consejo y no sin algún ethimo. Además de semejanzas en los ritos, sacrificios, vestiduras, calzado, mantos, cabello largo, la pusilanimidad y los templos de los dioses construidos en las crestas de los cerros y de las montañas. Aquello que fue predicho por los profetas de Israel parece corresponder, de manera admirable, con los acontecimientos de estas gentes. No hay que omitir, dice Hernández, que la prole de unos y otros es abundantísima, y los sacrificios, semejantes.

Francisco Hernández también habla de la vecina ciudad de Texcoco, a la cual ubica como más antigua que la mexicana, aunque confederada del imperio mexicano en el pináculo de este. Calcula que vivían en ella 100.000 varones, si se cuentan las aldeas y los pueblos, y que su lugar era "campestre, junto a la orilla de la laguna, dentro del valle de las montañas mexicanas, distante de la ciudad de México por el camino del lago sólo quince millas, y por el terrestre, treinta y cinco". Su cielo era "clemente y saludable y de una temperatura dulce y admirable, inclinándose un tanto, sin embargo, a fría y húmeda", por lo que no padece las enfermedades de la capital mexicana.

Las casas estaban diseminadas en todas direcciones, "separadas una de las otras, y en gran parte situadas como las de los pueblos"; llama su atención el que los texcocanos, "alrededor y cerca de cada una de ellas, hacen sementeras de todo lo que es en primer lugar necesario para la vida", de tal forma "que no creerías ver ciudades, sino los huertos de las Hespérides y campos amenísimos que se extienden a lo lejos".

En la región se han introducido ya "manadas de ganado caballar y lanar y de cereales indígenas y de los nuestros", y se practica la "cacería de liebres, de ciervos y de muchas clases de aves, de la mejor carne de cuadrúpedos", y posee también "fuentes de aguas limpidísimas y dulcísimas". A juicio de Hernández, no son ricos por carecer de minas de oro y de plata, en tanto que "dedican todo su tiempo al comercio, a la agricultura, al ganado lanar y a otras cosas semejantes; sobre todo los colonos españoles, los que son poco más o menos cien". 
Apreció la grandeza de Texcoco por medio de "dos palacios reales de los cuales quedan hoy vestigios". Uno de ellos, dentro de la ciudad y junto a la plaza donde se celebran los mercados que acostumbran los indios semanariamente. La construcción era admirable:

...por la amplitud de las aulas, por el número (como indican las ruinas y vestigios de los antiguos edificios) de los patios y arquitrabes; por la firmeza de la obra, por lo grande de las columnas y vigas, por la consistencia, esplendor y duración de los pavimentos de cal y piedra tezontli y además por los terraplenes y fosos revestidos de una y otra parte de piedra y para mayor solidez construidos en talud.

El otro se ubicaba en la ladera del monte Tetzcotonci, a unas millas de Texcoco, muy semejante al precedente, pero "digno de verse por dos mil o más escalones de piedra".

Como buen médico, observa la salubridad de las casas de los príncipes y de los varones, que se construían "de piedras con junturas apenas perceptibles, esculturas artísticas y de guijarros de varias formas a la fábrica amplia y muy bien fortificada con árboles y selvas ceñidas".

El pensamiento de Francisco Hernández plasmado en estos capítulos de las Antigüedades de la Nueva España tiene una connotación hipocrática. La descripción que hace de esas Antigüedades, en tanto ligadas a la historia moral, encuentra fundamento en las lecciones que el médico griego brinda a sus alumnos; como buen discípulo, la observación que hace de los lugares la basa en el mundo físico, y con ello busca la relación con el lado humano, aunque descaradamente, en ideas deterministas propias de la época y vigentes hasta nuestros días, particularmente hacia el indio vivo, con el que le toca convivir; de ahí las pormenorizadas descripciones que hace de él, pero elogia, desde luego, al indio muerto; esto, en relación con las ruinas admirables que le toca observar en Texcoco.

La observación, como un parámetro propio de la medicina del siglo XVI, le permitió a Hernández acercarse a la relación entre el mundo natural y el moral, partiendo también de la unidad cósmica: las partes que no pueden quedar aisladas, y, por lo mismo, es necesario cuantificarlas, con el fin de comprender a las sociedades que están siendo vistas. La observación, en términos hipocráticos, implicaba desmenuzar las partes del mundo natural, pero no perder de vista su manifestación en mundo moral. Esta conexión también ocupa aspectos que la medicina hipocrática dictaba para las enfermedades, que eran vistas como un desequilibrio cósmico.

Ese desequilibrio le permite señalar que los indios "son de naturaleza flemática y de paciencia insigne", y lamenta la decadencia que sufrirán los españoles en estas tierras, por lo que implora que "obedientes al cielo, no degeneren, hasta adoptar 
las costumbres de los indios". El concepto de "enfermedad" en el ámbito cósmico se manifestó en ese desequilibrio. Desde luego que no se puede hablar de "indios enfermos", pero sí podemos enfatizar que el ambiente no guardó esa mesura con el hombre americano, y, por lo mismo, no fueron favorables las condiciones para el bienestar humano. La historia de los hombres vista en el esquema de las Antigüedades guarda la visión de un mundo natural al que no es posible superar. 


\section{Bibliografía}

Acosta, Joseph de. Historia natural y moral de las Indias en que se tratan las cosas notables del cielo, elementos, metales, plantas y animales de ellas y los ritos y ceremonias, leyes y gobierno de los indios. [Edición preparada por Edmundo O'Gorman]. 2a. ed. México: Fondo de Cultura Económica, 1985.

Álvarez Peláez, Raquel. La conquista de la naturaleza americana. Madrid: CSIC, 1993.

Arismendi, Andrea. "Los estados de ánimo en la medicina española de los siglos XVI y XVII". Revista de Historia y Humanidades Médicas. 3. 2 (2007).

Debus, Allen G. El hombre y la naturaleza en el Renacimiento. México: Fondo de Cultura Económica. 1985.

Hernández, Francisco. Las antigüedades de la Nueva España. [Estudio introductorio de Ascensión Hernández de León Portilla]. Madrid: smd, 1986.

Hipócrates. Tratados hipocráticos. "Sobre los aires, aguas y lugares". Madrid: Gredos, 2000.

León Portilla, Ascensión H. y Hernández, Francisco. Antigüedades de la Nueva España y libro de la conquista de la Nueva España. Obras Completas. T. 6 Madrid: Dastin, 1984.

Martínez, Enrico. Repertorio de los tiempos y de historia Natural de la Nueva España [introducción de Francisco de la Maza; apéndice bibliográfico de Francisco González de Cossío, seguido del ensayo biográfico de Francisco de la Maza]. México: Novum, 1991.

Musset, Alain. "Lo sano y malsano en las ciudades españolas de América (siglos XVI-XVII)". Estudios sobre historia y ambiente en América I, Argentina, Bolivia, México, Paraguay. [Bernardo García y Alba González Jácome, comp.]. México: El Colegio de México-Instituto Panamericano de Geografía e Historia, 1999.

Pardo Tomas, José. El tesoro natural de América. Colonialismo y ciencia en el siglo XVI. Madrid: Nivola, 2002. 
Pimentel, Juan. "Cuadros y escrituras de la Naturaleza". Asclepio 56. 2(2004):7.

Ramírez, Marcelo. "Microcosmos: el hombre del Nuevo Mundo y la tradición grecolatina". Estudios de historia novohispana. 21 (2000): 13-47.

Samolinos D'Ardois, Germán. "Vida y obra de Francisco Hernández". Obras completas de Francisco Hernández, protomédico e historiador del Rey de España, Don Felipe II, en las Indias Occidentales, Yslas y Tierra Firme del Mar Océano. T. 1. México: Universidad Nacional Autónoma de México, 1960, 194-224.

Trabulse, Elías. "El erasmismo de un científico. Supervivencias del humanismo cristiano en la Nueva España de la contrarreforma". Historia Mexicana 28. 2 (1978).

Viveros, Germán. Hipocratismo en México: Siglo XVI. México: Universidad Nacional Autónoma de México, Instituto de Investigaciones Históricas, 1994.

Fecha de recepción: 17 de julio de 2008

Fecha de aprobación: 25 de septiembre de 2008 